\title{
Audit of Minimally Invasive Hysterectomy Rates: A Canadian Retrospective Cross-Sectional Database Review
}

\author{
Devon Evans $^{1 *}$, Margaret Burnett ${ }^{1}$ \\ ${ }^{1}$ Department of Obstetrics, Gynecology and Reproductive Sciences, Rady Faculty of Health Sciences, University of \\ Manitoba, Winnipeg, Canada
}

*Corresponding Author: Devon Evans, M.D., Department of Obstetrics, Gynecology and Reproductive Sciences, Rady Faculty of Health Sciences, University of Manitoba, Winnipeg, Canada. Tel: 204-891-2348, Email: devoncevans@gmail.com

Received September 25, 2017; Accepted November 21, 2017; Online Published January 28, 2018

\begin{abstract}
Background: Minimally invasive hysterectomy is generally preferable to abdominal hysterectomy. The technicity index (TI) is the proportion of hysterectomies performed by minimally invasive surgery. Many centers globally have started to audit local $\mathrm{TI}$ as a quality indicator, but only a handful have published their results to help define international standards of care. Objective: In this study, TI was examined in Winnipeg and Canada to determine consistency between local and national patterns of practice, audit expected changes, and contribute to the growing body of literature defining international standards of care.

Methods: A retrospective cross-sectional database review of hysterectomies performed in the Winnipeg Regional Health Authority (WRHA) from 2008 to 2015 was conducted. Mixed effects linear regression models were generated primarily to analyze $\mathrm{TI}$ and account for surgeon and hospital characteristics. The Canadian Institute for Health Information (CIHI) database was accessed to estimate the average national TI from 2009 to 2014 . One-sample t tests compared annual WRHA and $\mathrm{CIHI}$ TI.

Results: In Winnipeg, $1363 \pm 32$ hysterectomies were performed annually for all indications with an average $\mathrm{TI}$ of $34 \%$ independent of time $(P=0.09)$. The $\mathrm{CIHI}$ database recorded approximately 27000 hysterectomies annually with increasing TI $(41 \%-52 \%, 3.5 \pm 1.8 \%$ /year, $P=0.025)$. WRHA TI differed from national TI every year $(P<2.2 \times 10-16)$.

Conclusion: Over the study period, WRHA TI was below the Canadian average and static despite national increases. The importance of local audits to identify underperformance and stimulate initiatives for quality improvement is highlighted in this study.

Keywords: Hysterectomy, Minimally Invasive Surgery, Laparoscopic Surgery, Quality of Healthcare
\end{abstract}

\section{Background}

Other than caesarian section, hysterectomy is the most commonly performed procedure for women in Canada. ${ }^{1}$ Minimally invasive approaches performed by skilled gynecologists are superior to the conventional laparotomy in terms of patient morbidity, recovery time, and length of stay. ${ }^{2-4}$ Certain forms of minimally invasive hysterectomy may offer benefits in terms of hospital costs and faster return to economic productivity. ${ }^{5-7}$ The support for minimally invasive hysterectomy in benign disease is reflected in national and international guidance statements, all of which indicate that vaginal hysterectomy should be the firstchoice technique, followed by laparoscopic hysterectomy when vaginal hysterectomy is not possible..$^{8-10}$ Abdominal hysterectomy should be reserved for those patients who are not candidates for any minimally invasive approach.

Despite the abundance of evidence and clear professional guidelines, as of the most recently published data available, in 2008-2009, 54\% of all hysterectomies in Canada were still performed abdominally. ${ }^{1}$ Previous caesarean section, large uterine fibroids, and lack of uterine descent are some reasons commonly cited for avoiding vaginal hysterectomy, ${ }^{11}$ and training remains an issue for laparoscopic and robotic surgical techniques. ${ }^{12}$

The technicity index (TI) is defined as the sum of all vaginal, laparoscopic, and robotic hysterectomies divided by the total number of hysterectomies performed by any route for a given surgeon or institution in one year. ${ }^{13}$ Given

Copyright $(2018$ The Author(s). This is an open-access article distributed under the terms of the Creative Commons Attribution License (http:// creativecommons.org/licenses/by/4.0), which permits unrestricted use, distribution, and reproduction in any medium, provided the original work is properly cited. 
the abundant evidence demonstrating the superiority of the minimally invasive hysterectomy over the open hysterectomy, TI can be considered a measure of surgical performance, and trends over time may provide an objective indication of progress towards improving patient care. ${ }^{14}$

Since the advent of laparoscopy and recognition of the superiority of minimally invasive approaches to hysterectomy, many centers worldwide have started to publish their TIs for hysterectomy and add to the growing body of literature defining standards of care. The Finnish national TI improved from $42 \%$ in 1996 to $79 \%$ in $2006 .{ }^{15}$ The gynecologic department of Clermont-Ferrand in France reported a TI of $90 \%$ in $2008 .{ }^{13}$ In the United States, a recent multicenter analysis of high volume gynecologists reported an overall improved TI from $40 \%$ in 2005 to $78 \%$ in 2013. ${ }^{16}$ Similarly, another large multicenter initiative in California improved overall TI from 38\% in 2005 to $78 \%$ in $2010 .{ }^{17}$ The TI is also emerging in the gynecologic oncology literature as a quality indicator for hysterectomy for endometrial cancer. ${ }^{14}$

Several Canadian centers have published their experiences by trending TI in hysterectomy for benign disease. Vancouver, British Columbia improved minimally invasive hysterectomy rates from 2007 to 2011 from $41.6 \%$ in 2007 to $52.3 \%$ in $2011 .^{18}$ Ottawa, Ontario has demonstrated the greatest published national improvement from a TI of $40.1 \%$ in 2005 to $74.2 \%$ in 2012. ${ }^{7}$ As a province, Quebec improved from 39.9\% in 2002 to $44.3 \%$ in 2008. ${ }^{19}$ Winnipeg, Manitoba provides healthcare services for benign and malignant gynecologic disease to much of the province of Manitoba and some of Nunavut and Northwestern Ontario. In this health region, educational programs and equipment have been made available to encourage performance of minimally invasive hysterectomy for both benign and oncologic indications when feasible. However, no one has formally calculated the TI or audited expected improvements in this region.

This study examined minimally invasive hysterectomy rates in Winnipeg from 2008 to 2015 and in Canada from 2009 to 2014. It included all hysterectomies performed for any indication, given that minimally invasive hysterectomy is not limited to benign or malignant disease $\mathrm{e}^{13,14}$ and can be safely performed even in cases complicated by complex pathology. ${ }^{20}$

\section{Objective}

The objectives of this analysis were to determine how Winnipeg is performing relative to Canada and whether Winnipeg has improved minimally invasive hysterectomy rates over time. From an academic perspective, this study contributes to the small, but growing body of literature exploring TI for hysterectomy to help define international standards of care. From a patient care perspective, it serves as an audit of quality of care provided to patients in Winnipeg and provides objective evidence to motivate future interventions.

\section{Methods}

After local ethics approval was obtained, the authors conducted a cross-sectional retrospective database review of all hysterectomies performed during every fiscal year from March 31, 2008 to March 31, 2015 for benign or malignant conditions by all gynaecologists including generalists, reproductive endocrinology and infertility subspecialists, urogynecologists, and gynaecologic oncologists at all hospitals in Winnipeg including Health Sciences Centre and Saint Boniface Hospital (tertiary care referral-based hospitals) and Victoria General Hospital, Grace Hospital, and Seven Oaks General Hospital (community hospitals). A randomly generated number sequence was assigned to uniquely identify each hospital and surgeon during the analysis. TI and the number of procedures performed annually were calculated for each surgeon at each site during each fiscal year studied. To avoid skewing results by very low-volume surgeons, data were excluded from analysis in years where a surgeon performed less than three procedures at a center. The cases were examined retrospectively using a local surgical database maintained by the Winnipeg Regional Health Authority (WRHA). All hysterectomies classified as total laparoscopic or laparoscopic-assisted (1.RM.89.DA or 1.RM.89.AA), total vaginal (1.RM.89.CA), total open (1.RM.89.LA), radical laparoscopic or laparoscopicassisted (1.RM.91.DA or 1.RM.91.AA), radical vaginal (1.RM.91.CA), radical open (1.RM.91.LA), and subtotal (1.RM.87.GAX and 1.RM.87.DAX) were tabulated. Using the statistical software $\mathrm{R}^{21}$ and statistical package lme $4,{ }^{22}$ mixed effects linear regression models were generated to identify statistically significant trends in TI and number of hysterectomies performed annually while accounting for within-hospital clustering and non-independence due to repeated measures of surgeons at different hospitals and across fiscal years. Given that there is no validated set of variables that determine minimally invasive hysterectomy rates, only the variables available in the database that could theoretically affect an individual surgeon's practice patterns were examined. Surgeon and hospital were assigned as random effects, and fiscal year, hospital type (tertiary or community), and surgeon year of residency graduation, gender, and subspecialty were assigned as fixed effects. The Wald (normal) approximation was used to convert the t-statistics generated to two-tailed $P$ values for each of the fixed effects and 95\% CIs were generated in R. ${ }^{21}$ To optimize comparison with other centers, separate analyses were also performed for cases performed by benign gynaecologists (generalists and non-oncologic subspecialists) and gynaecologic oncologists. Conversion rates were also noted.

The Canadian Institute for Health Information (CIHI) provides limited access to Discharge Abstract Database (DAD) information for educational institutions through the online database Odesi. DAD information is currently available for fiscal years 2009-2011, 2011-2013, and 2014. The DAD is a $10 \%$ sampling of all International 
Classification of Diseases-10 (ICD-10) discharge diagnoses and Canadian Classification of Health Intervention (CCI) codes for patients nationwide, excluding British Columbia and Quebec. The CIHI database was accessed to estimate national TI from 2009 to 2014. Although cases with the Canadian CCI code 1.RM.87.^^ (partial hysterectomy) were included in the local database review, these cases were excluded from the CIHI database analysis due to excessively broad inclusion criteria not involving hysterectomy. Whereas the coding system in the CIHI database does not clearly indicate which subset of these coded cases are subtotal hysterectomies versus dilation and curettages, hysteroscopic procedures, or myomectomies, the local database specifically identified hysterectomy cases. One-sample $t$ tests were used to compare WRHA TI with Canadian TI. Finally, a brief online qualitative survey was sent to WRHA benign gynecologists to determine whether they felt they were optimizing their individual TIs.

\section{Results}

Over the study period, WRHA TI was below the Canadian average and static despite national increases (Figure 1). The CIHI database recorded approximately 27000 hysterectomies annually with increasing TI (41\%$52 \%$, linear increase $3.5 \pm 1.8 \%$ /year, $P=0.025)$, higher than the WRHA every year $\left(P<2.2 \times 10^{-16}\right)$. In the WRHA, $1059 \pm 65$ hysterectomies were performed annually by all benign gynecologists ( $23 \pm 6$ per surgeon) with an average TI of $40 \%$ (25\% vaginal, $15 \%$ laparoscopic) and conversion rate of $2.5 \%$. Gynecologic oncologists performed $303 \pm$ 42 hysterectomies annually (66 \pm 20 per surgeon) with an average TI of $14 \%$ ( $1 \%$ vaginal, $13 \%$ laparoscopic) and conversion rate of $21 \%$. From 2008 to 2015, most conversions were from the laparoscopic approach to laparotomy. Only 5 vaginal hysterectomies were converted to laparotomy in the 7-year study period, all by benign gynecologists. Overall, TI was highly surgeon-dependent (intra-class correlation 44\%), but, as presented in Table 1, unrelated to hospital type $(P=0.69)$ or surgeon gender $(P=0.75)$, year of residency graduation $(P=0.07)$, or subspecialty (reproductive endocrinology and infertility $P=0.09$, urogynecology $P=0.40)$ except gynecologic oncology $(-20 \%$ relative to generalists, $P=0.02)$. There was a small, but statistically significant increase in TI for surgeons who graduated residency more recently $(+0.83 \% /$ year, $\left.P=1.3 \times 10^{-5}\right)$. The online survey found that $41 \%$ (13/22 respondents) of WRHA benign gynecologists did not feel they should improve their own TI.

The number of hysterectomies performed by each surgeon was similarly highly surgeon-dependent (intraclass correlation $42 \%$, but the overall, unchanged with time. $-0.16 /$ year/surgeon, $P=0.08$ ). Regression analysis (Table 1) identified statistically significant trends towards a greater number of hysterectomies performed annually by male surgeons $(+8.0 /$ year/surgeon, $P=0.044)$ and a statistically, but not clinically, significant annual decrease in the overall number of hysterectomies performed by surgeons who completed residency training more recently (-0.35/year, $P=0.018)$. Amongst the subspecialties, gynecologic oncologists performed more hysterectomies than generalists (+22/year/surgeon, $\left.P=2.5 \times 10^{-4}\right)$, REI surgeons performed fewer than generalists (-19/year/ surgeon, $P=0.037)$, and urogynecologists performed the same number as generalists $(+3.2 /$ year/surgeon, $P=0.80)$.

\section{Discussion}

Winnipeg is underperforming minimally invasive hysterectomy relative to national averages and has not improved over the last 8 years. In contrast, other centers across Canada have made significant improvements in

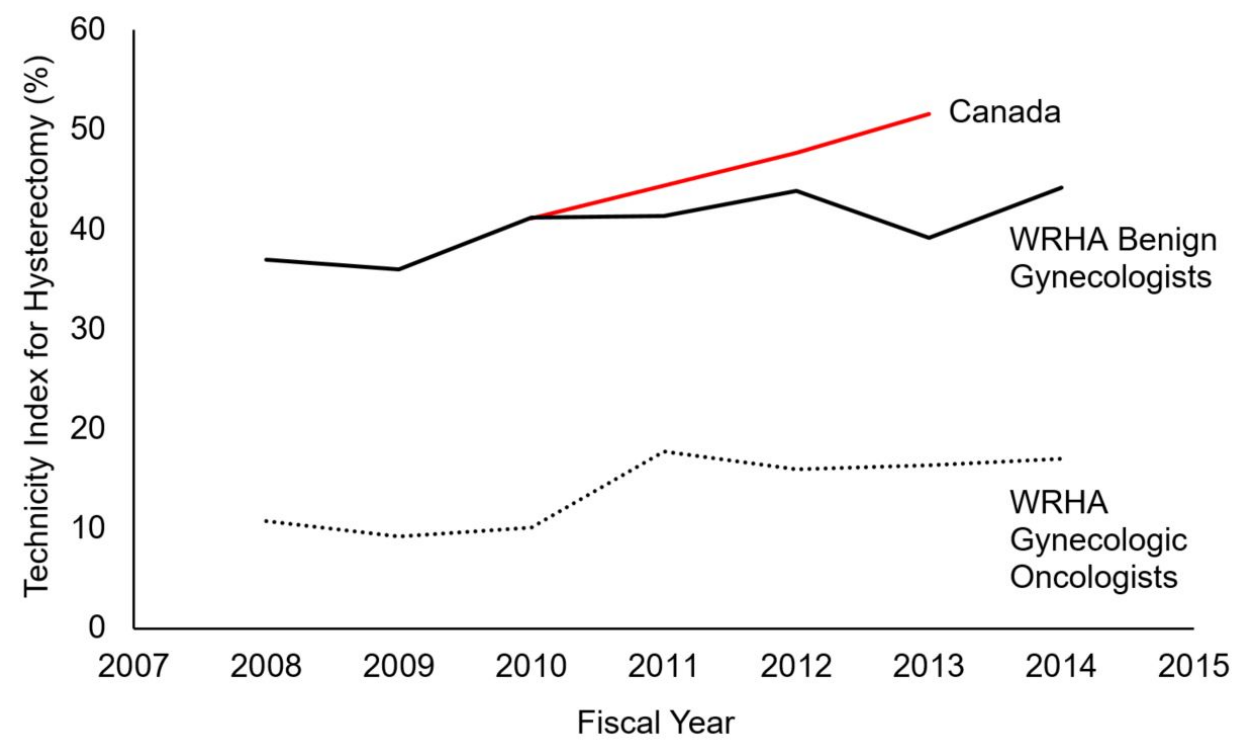

Figure 1. Technicity Index for Hysterectomy in Winnipeg (Winnipeg Regional Health Authority, WRHA) and Canada (Canadian Institute for Health Information, CIHI) From 2008 to 2015. Winnipeg data stratified by hysterectomies performed by benign gynecologists (general gynecologists, reproductive endocrinology and infertility specialists, and urogynecologists) and gynecologic oncologists. 
Table 1. Technicity Index for Hysterectomy and Number of Hysterectomies Performed Annually by Winnipeg Gynecologists

\begin{tabular}{|c|c|c|c|c|c|}
\hline & Time & $\begin{array}{c}\text { Hospital type (Relative to } \\
\text { Community) }\end{array}$ & Surgeon Gender & $\begin{array}{c}\text { Residency } \\
\text { Graduation Year }\end{array}$ & $\begin{array}{l}\text { Subspecialty } \\
\text { (Relative to Generalist) }\end{array}$ \\
\hline \multicolumn{6}{|l|}{ Technicity Index } \\
\hline All surgeons & $\begin{array}{c}+0.76 \% / y \\
(-0.12,1.6) \\
P=0.090\end{array}$ & $\begin{array}{l}\text { Tertiary }+2.5 \% \\
\quad(-10,18) \\
P=0.70\end{array}$ & $\begin{array}{c}\text { Male }+2.1 \% \\
(-9.8,14) \\
P=0.73\end{array}$ & $\begin{array}{c}+0.41 \% / y \\
(-0.033,0.86) \\
P=0.07\end{array}$ & $\begin{array}{c}\text { ONC: } \mathbf{- 2 0} \%(\mathbf{- 3 8}, \mathbf{- 2 . 6}), \boldsymbol{P}=\mathbf{0 . 0 2} \\
\text { REI: }+23 \%(-3.8,50), P=0.09 \\
\text { URO: }+16 \%(-21,53), P=0.39\end{array}$ \\
\hline Benign surgeons & $\begin{array}{c}+0.86 \% / y \\
(-0.12,1.9) \\
P=0.08\end{array}$ & $\begin{array}{l}\text { Tertiary }+2.1 \% \\
\quad(-11,18) \\
P=0.74\end{array}$ & $\begin{array}{c}\text { Male }+2.2 \% \\
\quad(-11,15) \\
P=0.73\end{array}$ & $\begin{array}{c}+0.38 \% / y \\
(-0.10,0.86) \\
P=0.12\end{array}$ & \\
\hline $\begin{array}{l}\text { Oncologic } \\
\text { surgeons }\end{array}$ & $\begin{array}{c}+0.20 \% / y \\
(-1.4,1.0) \\
P=0.74\end{array}$ & $\begin{array}{l}\text { NA (Oncology only at } \\
\text { tertiary centres) }\end{array}$ & $\begin{array}{c}\text { Male }+2.4 \% \\
(-8.5,15) \\
p=0.59\end{array}$ & $\begin{array}{c}+0.83 \% / y(0.29,1.3) \\
P=1.3 \times 10^{-5}\end{array}$ & \\
\hline \multicolumn{6}{|c|}{ Number of Hysterectomies } \\
\hline All surgeons & $\begin{array}{c}-0.16 / y / \text { surgeon } \\
(-0.74,0.42) \\
P=0.08\end{array}$ & $\begin{array}{c}\text { Tertiary } \\
-5.4 / y / \text { surgeon } \\
(-16,4.3) \\
P=0.26\end{array}$ & $\begin{array}{c}\text { Male } \\
+8.0 / y / \text { surgeon } \\
(0.084,16) \\
P=0.044\end{array}$ & $\begin{array}{c}-0.35 / y \\
(-0.65,-0.055) \\
P=0.018\end{array}$ & $\begin{array}{c}\text { ONC: }+\mathbf{2 2} / \mathrm{y} / \text { surgeon }(9.8,33), \\
\boldsymbol{P}=\mathbf{2 . 5 \times 1 0 ^ { - 4 }} \\
\text { REI: } \mathbf{- 1 9} / \mathbf{y} / \text { surgeon } \\
(-\mathbf{3 7}, \mathbf{- 0 . 7 6 ) ,} \boldsymbol{P}=\mathbf{0 . 0 3 7} \\
\text { URO: }+3.2 / \mathrm{y} / \text { surgeon } \\
(-22,28), P=0.80\end{array}$ \\
\hline Benign surgeons & $\begin{array}{c}-0.46 / y / \text { surgeon } \\
(-1.1,0.15) \\
P=0.14\end{array}$ & $\begin{array}{c}\text { Tertiary } \\
-4.9 / y / \text { surgeon } \\
(-15,4.6) \\
P=0.31\end{array}$ & $\begin{array}{c}\text { Male } \\
+7.1 / y / \text { surgeon } \\
(-1.7,16) \\
P=0.11\end{array}$ & $\begin{array}{c}-0.36 / y \\
(-0.68,-0.034) \\
P=0.028\end{array}$ & \\
\hline $\begin{array}{l}\text { Oncologic } \\
\text { surgeons }\end{array}$ & $\begin{array}{c}+1.6 / y / \text { surgeon } \\
(0.062,3.2) \\
P=0.038\end{array}$ & $\begin{array}{l}\text { NA (Oncology only at } \\
\text { tertiary centres) }\end{array}$ & $\begin{array}{c}\text { Male } \\
+12 / y / \text { surgeon } \\
(4.5,20) \\
P=1.5 \times 10^{-3}\end{array}$ & $\begin{array}{c}-0.13 / y \\
(-8.0,0.20) \\
P=0.43\end{array}$ & \\
\hline
\end{tabular}

Results of a mixed effects linear regression analysis. Statistically significant $(P<0.05)$ findings are bolded and highlighted in grey. Benign surgeons include general gynecologists, reproductive endocrinology and infertility specialists (REI), and urogynecologists (URO), and exclude gynecologic oncologists (ONC). Effect size, (95\% confidence interval), $P$ value.

performance in recent years, ${ }^{7,13,14,18}$ which demonstrates that change is possible in the Canadian context.

The strengths of this study include the robust statistical consideration of every hysterectomy performed by every surgeon at every center in Winnipeg over the time period studied and the contribution to the small but growing body of literature defining international standards of care for route of hysterectomy. To the best of our knowledge, we are the first group to publish minimally invasive hysterectomy rates for any indication with stratification by subspecialty.

A critical limitation to note is that this study was purely descriptive, and it was not possible with the information on hand to correlate individual patient characteristics or pathology with the findings. This considered, the benefits of minimally invasive hysterectomy, even in potentially complicating conditions like obesity, endometriosis, previous surgeries, and fibroid uteri, have been published elsewhere. ${ }^{20,23}$ This study has demonstrated the importance of performing local audits to identify discrepancies between expected and actual surgical performance. It is speculated that in many cases, surgeon rather than patient characteristics may dictate the route of hysterectomy. Regression analysis identified trends towards higher TI for surgeons who had graduated more recently from residency or had subspecialty training in benign disease (reproductive endocrinology and infertility or urogynecology), but there are many other variables not explored in this study. Despite practice recommendations and local resource availability, individual surgeon characteristics like attitude, experience, and practice profile may be important factors influencing TI. The qualitative online survey results would be consistent with this hypothesis as it indicated that there may be a lack of performance awareness amongst gynecologists who do not recognize the need to change their practices. More detailed analysis of determinants of TI can follow audits like this one to help tailor interventions to facilitate improvements.

Modern gynecological practice is changing with alternatives to hysterectomy becoming widely adopted. Although the current study found no significant decline in the absolute number of hysterectomies performed annually in Winnipeg, and the Manitoba provincial hysterectomy rate seems to have been static at 400 per 100000 women from $2010^{24}$ to the most recently published data in $2013,,^{25}$ hysterectomy rates will likely decrease in the future with improving medical alternatives. On average, benign gynecologists in Winnipeg currently perform only 23 hysterectomies annually, with some low-volume surgeons performing 3 or fewer hysterectomies annually. Already low surgical volumes in this demographic will likely create challenges in the future in terms of maintenance of surgical competency in minimally invasive techniques and translation of skills to trainees. The current study speaks to the need for urgent intervention to address the proportion of minimally invasive hysterectomy in Winnipeg hospitals.

\section{Conclusion}

Despite access to resources and training, gynecologists 
in Winnipeg are underperforming minimally invasive hysterectomy relative to other centers nationally and internationally. To better align Winnipeg's practice with similar centers, there is an urgent need to identify and address potential barriers to the performance of the minimally invasive hysterectomy in Winnipeg. The contribution made by this study to the growing body of literature describing minimally invasive hysterectomy rates highlights the importance of local audits to identify underperformance and stimulate initiatives for quality improvement.

\section{Authors' Contributions}

Study design: MB; Data collection: DE; Data analysis: DE; Manuscript preparation: DE and MB.

\section{Conflict of Interest Disclosures}

The authors declare no actual or potential conflicts of interest regarding the research, authorship, or publication of this article.

\section{Ethical Approval}

Ethical approval for this study was obtained from the University of Manitoba Bannatyne Campus Research Ethics Board.

\section{References}

1. Health Care in Canada 2010. Canadian Institute for Health Information (CIHI) website. 2010. https://secure.cihi.ca/ estore/productFamily.htm?pf=PFC1568\&lang=en\&media=0. Accessed October 20, 2017. Published 2010.

2. Nieboer TE, Johnson N, Lethaby A, et al. Surgical approach to hysterectomy for benign gynaecological disease. Cochrane Database Syst Rev. 2009(3):Cd003677. doi:10.1002/14651858. CD003677.pub4.

3. Donnez O, Jadoul P, Squifflet J, Donnez J. A series of 3190 laparoscopic hysterectomies for benign disease from 1990 to 2006: evaluation of complications compared with vaginal and abdominal procedures. BJOG. 2009;116(4):492-500. doi:10.1111/j.1471-0528.2008.01966.x.

4. Johnson N, Barlow D, Lethaby A, Tavender E, Curr L, Garry R. Methods of hysterectomy: systematic review and meta-analysis of randomised controlled trials. BMJ. 2005;330(7506):1478. doi:10.1136/bmj.330.7506.1478.

5. Thiel JA, Kamencic H. Assessment of costs associated with outpatient total laparoscopic hysterectom. J Obstet Gynaecol Can. 2006;28(9):794-798. doi:10.1016/s1701-2163(16)322587.

6. Jonsdottir GM, Jorgensen $\mathrm{S}$, Cohen $\mathrm{SL}$, et al. Increasing minimally invasive hysterectomy: effect on cost and complications. Obstet Gynecol. 2011;117(5):1142-1149. doi:10.1097/AOG.0b013e3182166055.

7. Gale J, Cameron C, Chen I, Guo Y, Singh SS. Increasing Minimally Invasive Hysterectomy: A Canadian Academic Health Centre Experience. J Obstet Gynaecol Can. 2016;38(2):141146. doi:10.1016/j.jogc.2015.12.004.

8. Lefebvre G, Allaire C, Jeffrey J, et al. SOGC clinical guidelines. Hysterectomy. J Obstet Gynaecol Can. 2002;24(1):37-61; quiz 74-36.
9. ACOG Committee Opinion No. 444: choosing the route of hysterectomy for benign disease. Obstet Gynecol. 2009;114(5):1156-1158. doi:10.1097/AOG.0b013e3181c33c72.

10. AAGL position statement: route of hysterectomy to treat benign uterine disease. J Minim Invasive Gynecol. 2011;18(1):1-3. doi:10.1016/j.jmig.2010.10.001

11. McCracken G, Lefebvre GG. Vaginal hysterectomy: dispelling the myths. J Obstet Gynaecol Can. 2007;29(5):424-428. doi:10.1016/s1701-2163(16)35494-9.

12. Chen I, Bajzak KI, Guo Y, Singh SS. A national survey of endoscopic practice among gynaecologists in Canada. J Obstet Gynaecol Can. 2012;34(3):257-263. doi:10.1016/s17012163(16)35186-6.

13. Laberge PY, Singh SS. Surgical approach to hysterectomy: introducing the concept of technicity. J Obstet Gynaecol Can. 2009;31(11):1050-1053. doi:10.1016/s1701-2163(16)34350-x.

14. Renaud MC, Plante M, Roy M. The technicity index: a useful performance indicator for minimally invasive surgery in the management of endometrial cancer. J Obstet Gynaecol Can. 2012;34(12):1180-1183. doi:10.1016/s1701-2163(16)354664.

15. Makinen J, Brummer T, Jalkanen J, et al. Ten years of progress--improved hysterectomy outcomes in Finland 1996-2006: a longitudinal observation study. BMJ Open. 2013;3(10):e003169. doi:10.1136/bmjopen-2013-003169.

16. Lim PC, Crane JT, English EJ, et al. Multicenter analysis comparing robotic, open, laparoscopic, and vaginal hysterectomies performed by high-volume surgeons for benign indications. Int J Gynaecol Obstet. 2016;133(3):359-364. doi:10.1016/j.ijgo.2015.11.010.

17. Andryjowicz E, Wray T. Regional expansion of minimally invasive surgery for hysterectomy: implementation and methodology in a large multispecialty group. Perm J. 2011;15(4):42-46. doi:10.7812/TPP/11-093.

18. Chen I, Lisonkova S, Allaire C, Williams C, Yong P, Joseph KS. Routes of hysterectomy in women with benign uterine disease in the Vancouver Coastal Health and Providence Health Care regions: a retrospective cohort analysis. CMAJ Open. 2014;2(4):E273-280. doi:10.9778/cmajo.20130080.

19. Bernatchez-Laflamme SM, Bujold E, Roberge S, Laberge PY. [Development of technicality indices of hysterectomies in Quebec]. J Obstet Gynaecol Can. 2013;35(2):144-148. doi:10.1016/s1701-2163(15)31019-7.

20. Grant-Orser A, El Sugy R, Singh SS. Does laparoscopy safely improve technicity for complex hysterectomy cases? J Obstet Gynaecol Can. 2014;36(3):248-252. doi:10.1016/s17012163(15)30633-2.

21. R_Core_Team. R Development Core Team. R: A language and environment for statistical computing. R Foundation for Statistical Computing; 2015.

22. Bates D, Mächler M, Bolker B, Walker S. Fitting Linear MixedEffects Models Using Ime4. J Stat Softw. 2015;67(1):48. doi:10.18637/jss.v067.i01.

23. Bogani G, Cromi A, Serati M, et al. Laparoscopic and vaginal approaches to hysterectomy in the obese. Eur J Obstet Gynecol Reprod Biol. 2015;189:85-90. doi:10.1016/j. ejogrb.2015.02.035.

24. Manitoba Health. Annual Statistics 2010-2011. Manitoba: Manitoba Health, Healthy Living and Seniors Health Information Management; 2010.

25. Manitoba Health. Annual Statistics 2013-2014. Manitoba: Manitoba Health, Healthy Living and Seniors Health Information Management; 2013. 